\title{
EXPERIMENTAL STUDY OF DECOMPRESSION, PERMEABILITY AND HEALING OF SILICATE ROCKS IN FAULT ZONES
}

\author{
V. Ya. Medvedev ${ }^{1}$, L. A. Ivanova ${ }^{1}$, B. A. Lysov², V. V. Ruzhich ${ }^{1}$, M. V. Marchuk ${ }^{1}$ \\ ${ }^{1}$ Institute of the Earth's Crust of SB RAS, Irkutsk, Russia \\ ${ }^{2}$ Irkutsk State University, Irkutsk, Russia
}

\begin{abstract}
The article presents results of petrophysical laboratory experiments in studies of decompression phenomena associated with consequences of abrupt displacements in fault zones. Decompression was studied in cases of controlled pressure drop that caused sharp changes of porosity and permeability parameters, and impacts of such decompression were analyzed. Healing of fractured-porous medium by newly formed phases was studied. After experiments with decompression, healing of fractures and pores in silicate rock samples $\left(3 \times 2 \times 2 \mathrm{~cm}, 500{ }^{\circ} \mathrm{C}, 100 \mathrm{MPa}\right)$ took about $800-1000$ hours, and strength of such rocks was restored to $0.6-0.7$ of the original value. In nature, fracture healing is influenced by a variety of factors, such as size of discontinuities in rock masses, pressure and temperature conditions, pressure drop gradients, rock composition and saturation with fluid. Impacts of such factors are reviewed.
\end{abstract}

Key words: physical experiment, decompression, permeability, fracture healing, earthquake.

\section{ЭКСПЕРИМЕНТАЛЬНОЕ ИЗУЧЕНИЕ ДЕКОМПРЕССИИ, ПРОНИЦАЕМОСТИ И ЗАЛЕЧИВАНИЯ СИЛИКАТНЫХ ПОРОД В ЗОНАХ РАЗЛОМОВ}

\author{
В. Я. Медведев ${ }^{1}$, Л. А. Иванова ${ }^{1}$, Б. А. Лысов ${ }^{2}$, В. В. Ружич ${ }^{1}$, М. В. Марчук ${ }^{1}$ \\ ${ }^{1}$ Институт земной коры СО РАН, Иркутск, Россия \\ ${ }^{2}$ Иркутский государственный университет, Иркутск, Россия
}

Аннотачия: Рассмотрены результаты петрофизических лабораторных экспериментов по изучению явлений декомпрессии, связанных с последствием скачкообразных смещений в зонах разломов. Измерялись и анализировались последствия декомпрессии при регулируемом спаде давлений, которая приводила к резкому изменению параметров пористости и проницаемости. Изучались процессы залечивания новообразованными фазами раскрывшегося трещинно-порового пространства. Показано, что после экспериментов с декомпрессией время заращивания трещин и 
пор образцов силикатных пород размером $3 \times 2 \times 2$ см при температуре $500{ }^{\circ} \mathrm{C}$, давлении 100 МПа составляет порядка 800-1000 часов с восстановлением их прочности 0.6-0.7 по отношению к исходной. Рассматривается влияние основных факторов: размеров нарушений сплошности породных массивов, РТ-условий, скачков градиентов давления, состава пород и насыщенности флюидом на процессы залечивания в природных условиях.

Ключевые слова: физический эксперимент, декомпрессия, проницаемость, залечивание разрывов, землетрясение.

\section{1. ВВЕДЕНИЕ}

Физико-химические процессы, происходящие в глубинных сегментах зон разломов литосферы, где формируются рудные месторождения, а также очаги землетрясений, остаются недостаточно изученными до настоящего времени. Отсюда высоковостребованными можно считать экспериментальные исследования, с помощью которых воспроизводятся и оцениваются разнообразные параметры декомпрессии, проницаемости и залечивания горных пород с учетом тех термодинамических и трибохимических условий, которые предполагаются на разных глубинных уровнях и в различных геодинамических обстановках, сопровождающих деформации в зонах разломов. С позиций тектонофизики и мезомеханики деструкция в литосфере является многоуровневым процессом, т.е. имеет место последовательное объединение мелких зародышевых трещин в более крупные, которые на следующем масштабном уровне также объединяются до стадий формирования внутриплитных и межплитных разломов в литосфере. Важно акцентировать внимание на следующих особенностях деструкции в литосфере. Морфология бортов магистральных разрывов при слиянии разномасштабных разрывов низшего иерархического уровня всегда характеризиуется шероховатостью, то есть идеально гладких разрывных нарушений в геологической обстановке не бывает. Следовательно, режимы смещений берегов разрывов при наличии исходной шероховатости, как правило, являются прерывистыми, о чем свидетельствуют многолетние высокоточные измерения смещений в разломах [Ruzhich et al., 1999]. Этому также способствуют разнообразные режимы деформирования литосферы Земли под влиянием эндогенных и внеземных энергетических источников, которые имеют выраженную волновую природу. Строение зон разломов представлено сочетанием выступов с пятнами контактного скольжения и участков относительного растяжения. Таким образом, в глубинных сегментах зон разломов при неравномерности смещений шероховатых поверхностей и взаимодействии неровностей всегда возможны быстрые перепады давлений и явления декомпрессии, приводящие к скачкообразному снижению литостатического и флюидного давления и интенсивному восходящему тепломассопереносу. Именно такие бароградиентные геологические системы моделировались лабораторными физическими экспериментами. В качестве объектов исследования авторами использовались две группы силикатных пород: амфибол-биотитовые гранодиориты (как равномерно-зернистые) и граниты-рапакиви (как неравномерно-зернистые породы).

\section{2. МЕТОДЫ ПРОВЕДЕНИЯ ЭКСПЕРИМЕНТА И ИЗМЕРЕНИЙ}

Эксперименты по декомпрессии силикатных пород проводились с целью петрохимического моделирования эндогенных процессов, происходящих в зонах разломов в условиях быстрых изменений скорости смещений. Использовалась аппаратура высокого давления, позволяющая работать в диапазоне температур 200-800 ㄷ и давлений 20-200 МПа при одновременном воздействии флюида системы C-O-H с контролируемым соотношением компонентов с амфибол-биотитовыми гранодиоритами и гранитами рапакиви. Сброс давления после необходимой изобарно-изотермической выдержки осуществлялся через специальный клапан, время сброса давления от 100 МПа до атмосферного 2-1800 с. Моделировались различные режимы диссипации (от постепенного приведения системы к стандартным условиям до шоковой декомпрессии). До и после экспериментов на образцах определялась проницаемость; кроме того, исследовались прочностные характеристики пород (удельная прочность на сжатие), и просматривались шлифы.

При изучении восстановления сплошности образцов путем залечивания их в гидротермальных условиях применялись стандартные автоклавы и экзоклавы с рабочим объемом 200 см $^{3}$ по следующей схеме (рис. 1). Образцы, ранее подвергнутые шоковой декомпрессии в условиях: давление 100 МПа, скорость сброса $50 \mathrm{MПа/c,} \mathrm{температура} 500{ }^{\circ} \mathrm{C}$, помещались в автоклав, где и происходило их залечивание в течение необходимого времени.

Изучение петрофизических свойств горных пород проводилось в лаборатории физики нефтяного и газового пласта (ФНП) Иркутского государственного университета на стандартной аппаратуре типа AKM, а также на созданных в лаборатории приборах. Исследования были выполнены на образцах, изготовленных в 


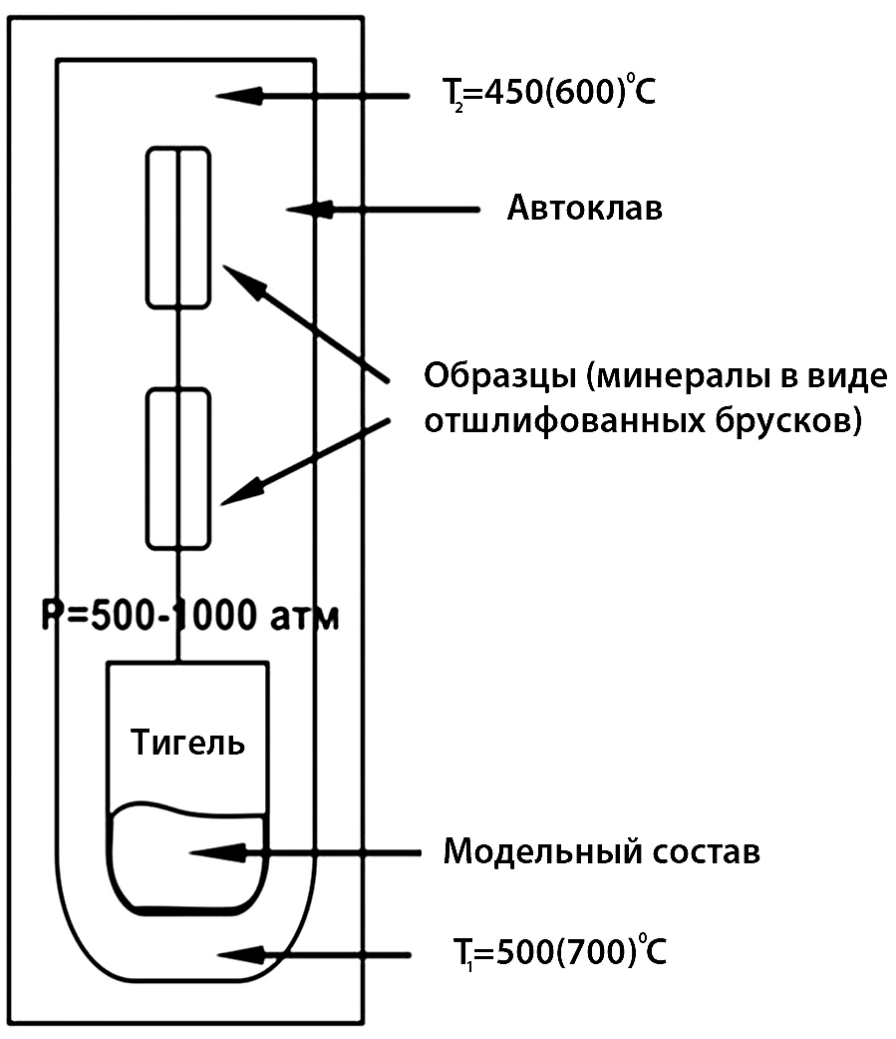

Рис. 1. Схема рабочей установки.

Fig. 1. Installation scheme.

виде цилиндров диаметром $d=(2.44-2.51) \cdot 10^{-2}$ м, высотой $h=(1.0-2.5) \cdot 10^{-2}$ м и объемом $V=(4.9-10.0) \cdot 10^{-6} \mathrm{~m}^{3}$. Всего проанализировано порядка ста образцов горных пород. Определялось шестнадцать параметров, представленных в таблицах 1, 2.

Емкостная характеристика порового пространства пород изучалась по газу $\left(N_{2}\right)$ с помощью коэффициента открытой пористости, который определялся по формуле:

$$
K_{\text {оп }}=\left(1-\frac{\rho_{\text {обр }}}{\rho_{\text {т.ф. }}}\right) \cdot 100 \%,
$$

где $K_{\text {оп }}$ - коэффициент открытой пористости (\%); $\rho_{\text {обр }}$ объемная плотность породы; $\rho_{\text {т.ф. }}-$ плотность твердой фазы (минеральной части) образца.

Определение объемной плотности образцов проводилось тремя независимыми методами: гидростатическим взвешиванием; денсимером; по массе и объему, найденному простым геометрическим обмером образцов. Плотность твердой фазы образцов находилась по массе и объему минеральной части, который определялся на приборе КОФСП (комплексный определитель физических свойств породы), созданном в лаборатории ФНП. Принцип действия прибора основан на использовании закона Менделеева-Клапейрона, рабочим агентом служит газ. Следует отметить, что использо- вание газа является единственным надежным способом определения малых значений емкости порового пространства представленных образцов горных пород. Точность прибора определялась эталонированием.

Динамические (фильтрационные) характеристики порового пространства образцов исследовались с помощью коэффициента проницаемости $\left(K_{\text {пр }}\right)$, определяемого в основном на приборе КОФСП и в единичных случаях - на УИПК (универсальный исследователь проницаемости кернов) по газу $\left(N_{2}\right)$. Максимальное рабочее давление равнялось 0.6 МПа, давление обжима образцов - 1.11 МПа при температуре 293 K, т.е. условия фильтрации были близки к стандартным (лабораторным).

Для нахождения $K_{\text {пр }}$ использовалась двучленная формула:

$$
I=a Q+b Q^{2},
$$

где $I$ - градиент давления; $a, b$ - фильтрационные коэффициенты; $Q$ - расход газа.

Данный способ определения $K_{\text {пр }}$ отличается от общепринятого, основанного на линейном сопоставлении среднего градиента давлений и среднего расхода газа, проходящего через образец. Коэффициент проницаемости рассчитывался по фильтрационному коэффициенту $a$, определенному графическим или аналитическим способом в комбинированных координатаx:

$$
\frac{\left(P_{1}+P_{2}+2 P_{6}\right)\left(P_{1}-P_{2}\right)}{Q}=f(Q),
$$

где $P_{1}$ - давление на входе в образец; $P_{2}$ - давление на выходе из образца; $P_{6}$ - барометрическое давление. Полученные таким образом значения фильтрационного коэффициента $a$ меньше определяемых по стандартной методике, поэтому коэффициент проницаемости, найденный следующим образом:

$$
K_{n p}=\frac{2 P_{\sigma} \mu h}{a F}
$$

где $\mu$ - вязкость газа (МПа.с); $h$ - длина образца; $F$ площадь фильтрации, оказывается выше рассчитанного традиционным путем.

Фильтрационный коэффициент $b$ характеризует структуру порового пространства пород и степень турбулентности потока газа.

Точность определения проницаемости зависит от герметичности изоляции образца и чувствительности приборов, определяющих перепад давления на концах образца и расход газа. Герметичность в экспериментах проверялась по фильтрации газа при максимально возможных перепадах давления через непроницаемый образец-эталон. Минимально возможное определяемое значение проницаемости $-1 \cdot 10^{-3}{\phi м^{2}}^{2}$. В коллекции представленных образцов наименьшее значение коэф- 


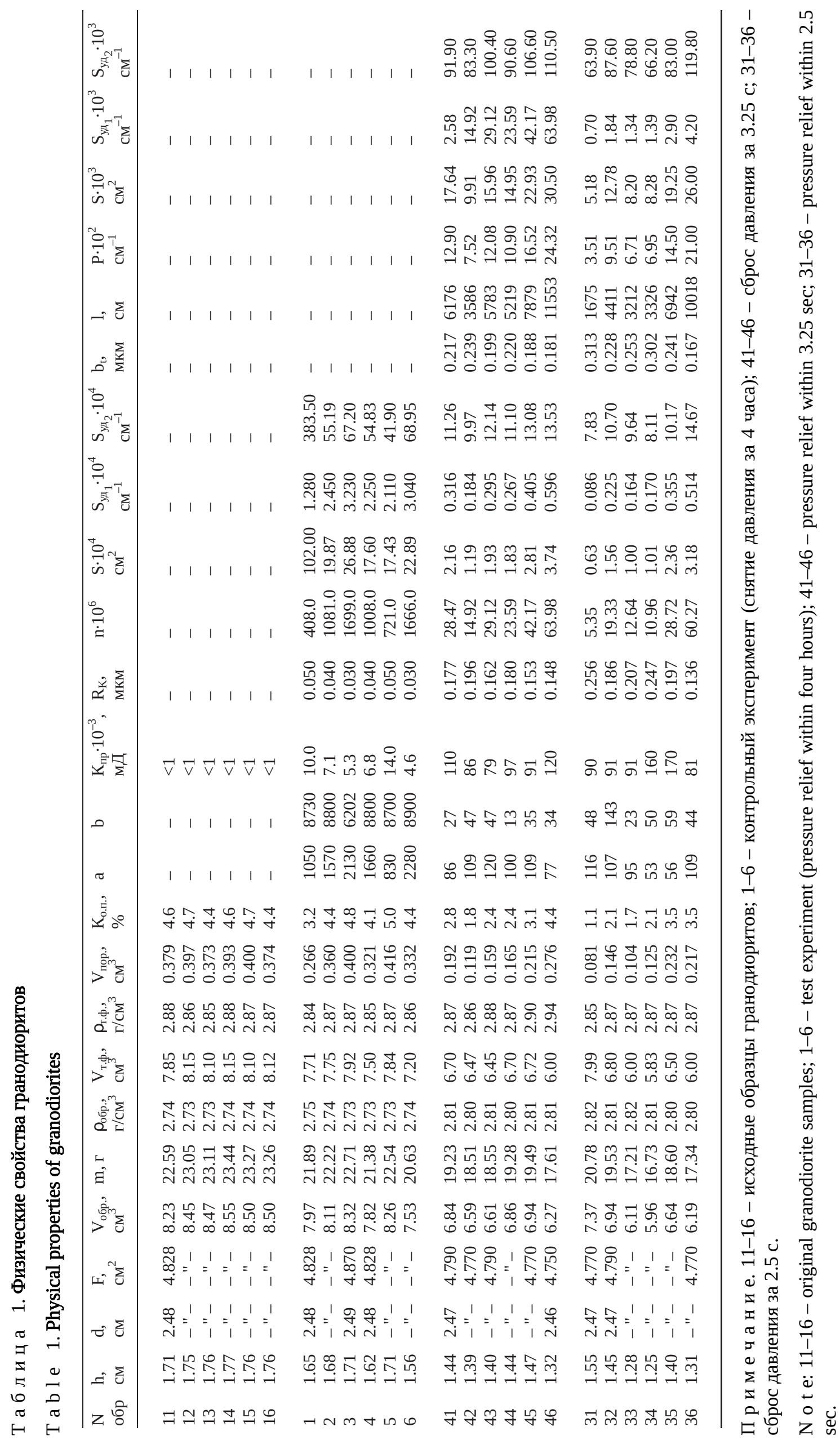




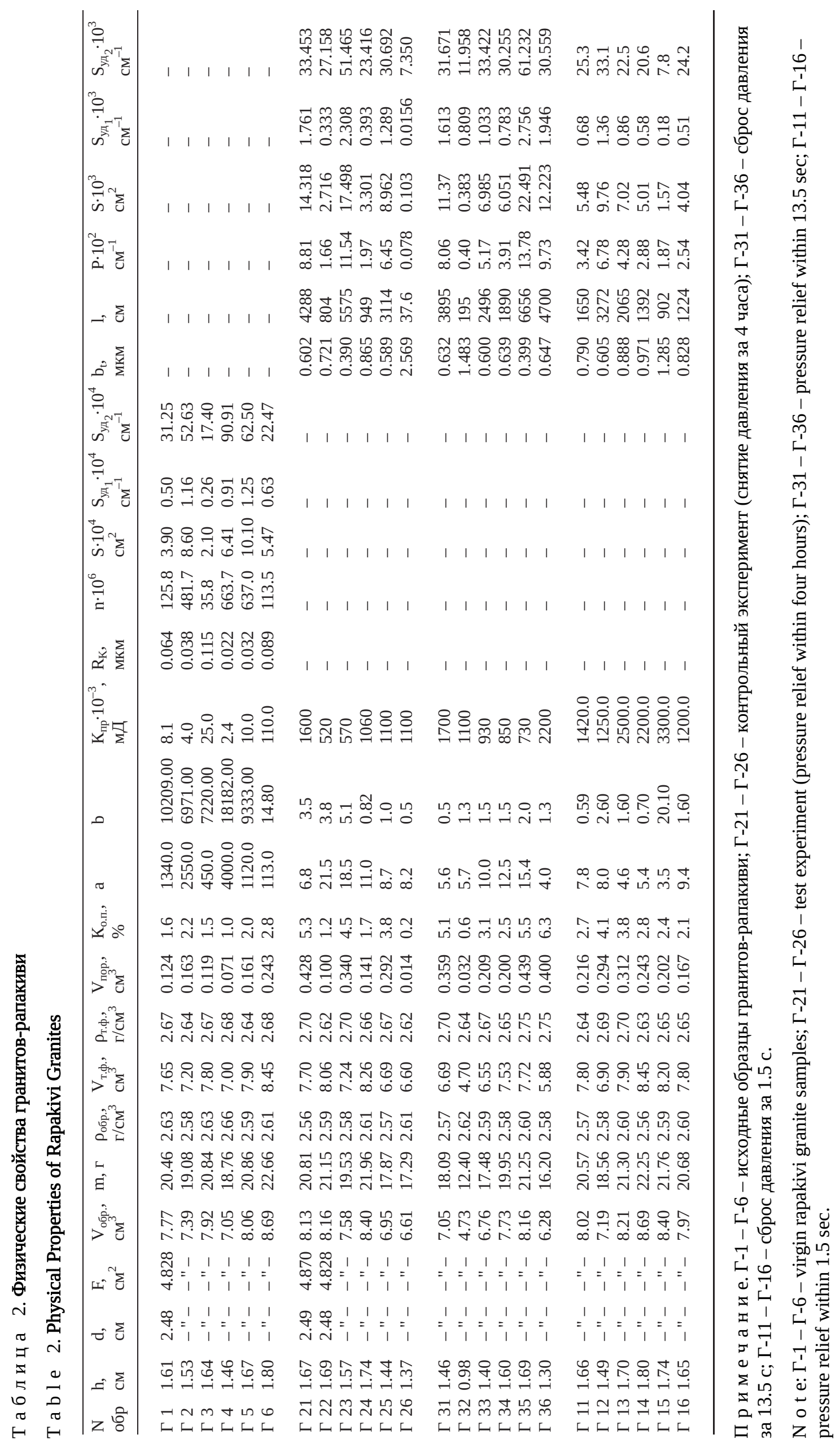


фициента проницаемости определено по образцу Г-4 и составило $K_{\text {пр }}=2.4 \cdot 10^{-3}{\phi \mathrm{m}^{2}}^{2}$, т.е. в два раза превышает минимально возможное значение.

Колебание проницаемости исследованных образцов значительное: разброс значений достигает 3000 фм² $^{2}$. Для образцов с минимальной проницаемостью определялись средний радиус капилляров (пор) $\bar{R}_{\kappa}$, число пор на единицу поверхности образца $n$, суммарная поверхность поровых каналов $S$, удельная поверхность на единицу объема образца $S_{\text {уд }}$ и на единицу объема порового пространства $S_{\text {уд }_{2}}$.

Средний радиус пор рассчитывался по формуле:

$$
\bar{R}_{K}=\sqrt{\frac{8 K_{n p} T^{2}}{K_{\text {оп }}}},
$$

где $T$ - извилистость поровых каналов. Для нахождения параметра $T$ необходимо проводить дополнительные исследования образца, которые пока не были осуществлены в силу технических трудностей, поэтому во всех расчетах $T$ принимается равным единице.

Размеры пор малы и изменяются от 0.02 до 0.70 мкм. Число пор на единицу поверхности образца определялось по формуле:

$$
n=\frac{K_{\text {оп }} T}{\pi \bar{R}_{\mathrm{k}}^{2}} \cdot 10^{12} .
$$

При минимальных значениях $\bar{R}_{\mathrm{k}}$ число пор достигало $6 \cdot 10^{9} \Pi / \mathrm{M}^{2}$, что говорит об однородной структуре порового пространства исследуемых горных пород, представленной огромной массой чрезвычайно малых пор.

Удельная поверхность в единице объема образца рассчитывалась через гидравлический радиус по формуле:

$$
S_{\text {уд }_{1}}=\frac{2 K_{\text {оп }}}{\bar{R}_{\mathrm{k}}} .
$$

Так как поверхность электростатически заряжена, очевидно то, что исследуемая порода может стать хорошим катализатором поверхностных явлений на границах сред.

Удельная поверхность на единицу объема порового пространства определялась по формуле:

$$
S_{\text {y }_{2}}=\frac{2}{\bar{R}_{\mathrm{k}}} \text {. }
$$

Естественно, что она значительно больше $S_{\text {уд }}$, но имеет более плавный характер колебаний, что позволяет с большой достоверностью разбивать образцы на группы с близкими адгезионными свойствами.

Для образцов, у которых проницаемость резко увеличивалась, вместо пяти последних параметров определялись шесть дополнительных параметров, характеризующих трещиноватость. При незначительных изменениях $K_{\text {пр }}$ рассчитывались все характеристики.
Определение раскрытия трещин $b_{\mathrm{t}}$ и длины системы трещин $l$ осуществлялось по закону Буссинеска:

$$
Q=l \frac{b_{t}^{2}}{12 \mu} \cdot \frac{\Delta P}{\Delta l},
$$

где $b_{\mathrm{t}}$ - раскрытость трещин; $\frac{\Delta P}{\Delta l}-$ градиент давления; $Q$ - расход газа; $l$ - длина системы трещин.

Поверхностная плотность трещин ( $\rho$ ) определялась по формуле:

$$
\rho=l \frac{l}{F},
$$

где $F$ - площадь фильтрации образца.

Для единой трещинной системы поверхностная плотность трещин совпадает с объемной, поэтому площадь поверхности трещин можно определить следующим образом:

$$
S=2 \rho V_{\text {обр }}
$$

где $S$ - площадь поверхности всех трещин в образце; $V_{\text {обр }}$ - объем образца.

Удельная поверхность единицы объема образца рассчитывалась по формуле:

$$
S_{\text {मд }_{1}}=2 \rho .
$$

Удельная поверхность в единице объема порового пространства определялась по формуле:

$$
S_{\text {уд }_{2}}=\frac{S}{\bar{V}_{\text {пор }}},
$$

где $V_{\text {пор }}$ - объем пор в образце.

Ошибки измерения всех физических свойств в абсолютном выражении в 2-4 раза меньше минимальных определенных значений соответствующих параметров, т.е. все определения являются значимыми.

\section{3. РЕЗУЛЬТАТЫ ИССЛЕДОВАНИЙ И ИХ АНАЛИЗ}

В более ранних экспериментах по декомпрессии силикатных расплавов было установлено, что при определенных режимах (в зависимости от скорости сброса давления) за счет вскипания расплава и резкого увеличения его объема (иногда почти десятикратно по отношению к первичному) происходит структурирование порового пространства формирующегося стекла [Letnikov et al., 1990]. При шоковой декомпрессии возникал столбик расплава, пронизанный системой тонких капилляров, вытянутых вдоль длинной оси (рис. 2). Таким путем формировалась высокоэффективная система флюидного массопереноса, реализация которой в подвергшейся декомпрессии магматической колонне весьма вероятна. 


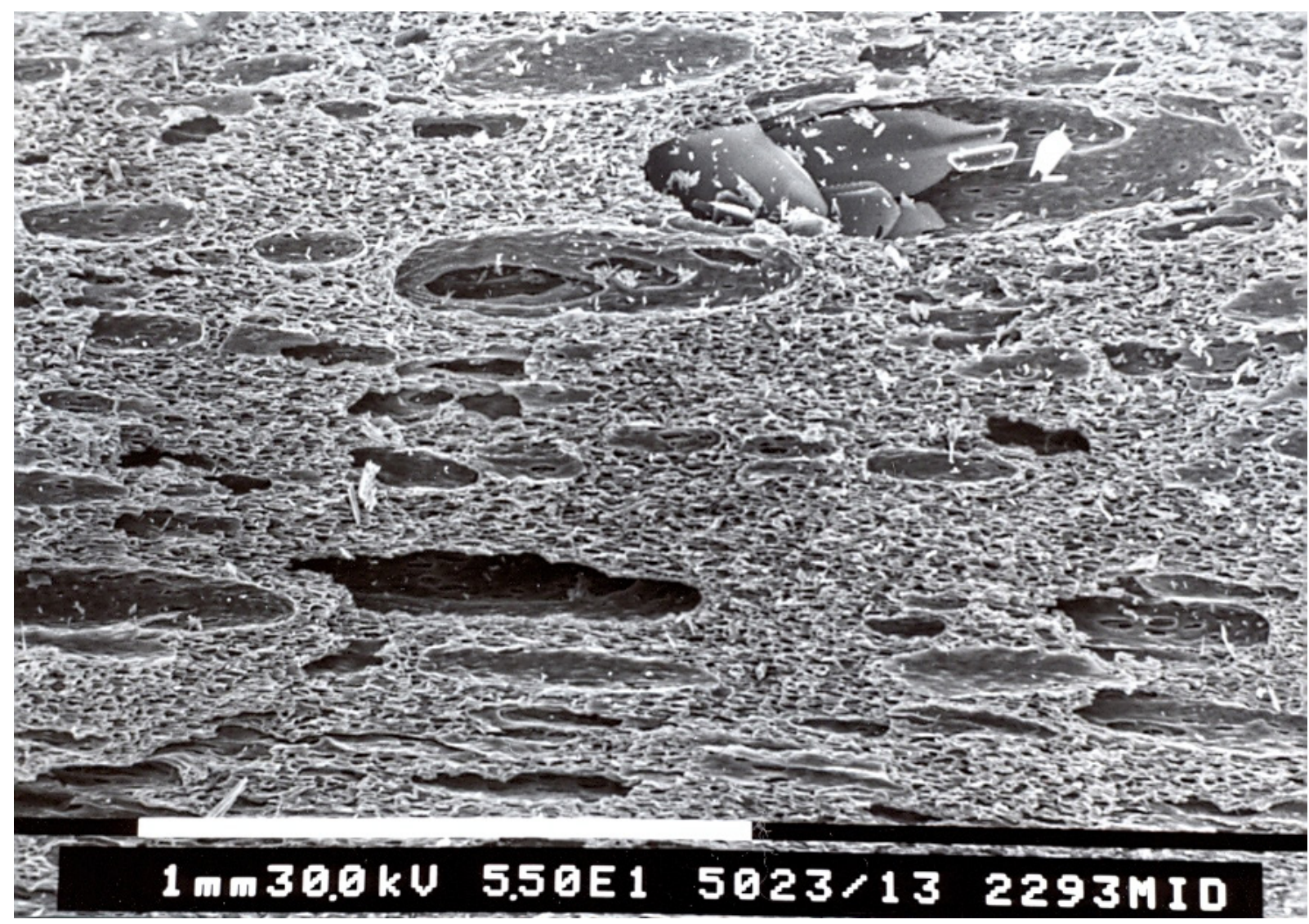

Рис. 2. Проводящие структуры в гранитном расплаве после сброса давления. $\mathrm{T}=850{ }^{\circ} \mathrm{C}, \mathrm{P}=2500$ атм., скорость сброса давления 2500 атм/с.

Fig. 2. Conductive structures in granitic melt after pressure drop. $\mathrm{T}=850{ }^{\circ} \mathrm{C} ; \mathrm{P}=2500 \mathrm{~atm}$; pressure relief rate $=2500 \mathrm{~atm} / \mathrm{sec}$.

С этой точки зрения интерес представляет проблема физического состояния горной породы при снятии литостатического и флюидного давления. Предполагалось, что декомпрессия образцов силикатных пород, помещаемых в условия высоких температур и давлений, соответствующих глубоким горизонтам земной коры, также приведет к определенным изменениям порового пространства [Medvedev et al., 1995; Balyshev et al., 1996].

При микроскопических исследованиях амфиболбиотитовых гранодиоритов, подвергнутых шоковой декомпрессии, сравнительно с исходными породами обнаруживаются следующие изменения. В биотите отчетливее проявляются трещины спайности, и повсеместно по этим трещинам выделяется мелкий рудный минерал черного цвета (магнетит или гематит). Чешуйки биотита становятся расщепленными, он как бы «разбухает», однако цвет его не меняется, а остается коричневым или светло-коричневым, как и в исходных породах. В плагиоклазах почти в каждом зерне появляются довольно широкие (до 0.02 мм) неминерализованные трещины. В крупных зернах наблюдается до 67 трещин, рассекающих зерно полностью или почти полностью. Нередко крупные трещины сопровожда- ются более мелкими «оперяющими». Зерна амфибола разбиты грубыми субпараллельными трещинами, в которых заметна (хотя и не повсеместно) хлоритизация, возникшая за время проведения эксперимента, что представляет несомненный интерес. Часто наблюдаются не открытые трещины, а зоны, где амфибол деформирован. Ширина таких зон порядка 0.012 мм. Многие крупные трещины не только рассекают отдельные зерна, но и проходят сквозь все минералы шлифа. Заметно увеличивается пористость породы за счет и трещин, и довольно крупных межзерновых пор овальной формы, причем размер последних достигает 0.8 мм.

В подвергнутых шоковой декомпрессии микроклиновых гранитах наблюдаются аналогичные явления: обилие мелких внутризерновых трещин, распространенных по всем слагающим породу минералам; развитие более крупных (до 0.12-0.15 мм) межзерновых трещин, переходящих в поры, и сквозных субпараллельных трещин, секущих все минералы шлифа.

Из изученных физических свойств наиболее закономерно и однозначно зависит от режима снятия давления проницаемость пород (рис. 3). При этом в случае максимально быстрого приведения системы к 


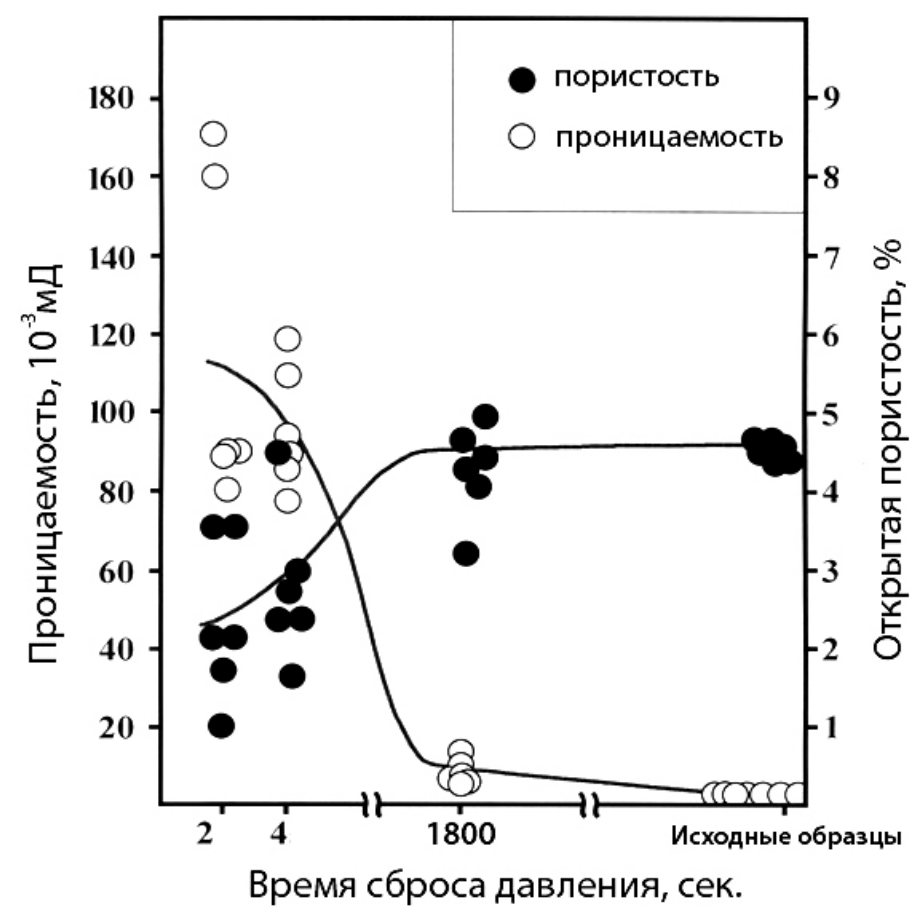

Рис. 3. Изменение проницаемости и открытой пористости в гранодиорите в зависимости от режима сброса давления.

Fig. 3. Changes of permeability and open porosity in granodiorite samples depending on pressure release mode.

стандартным условиям проницаемость гранодиоритов возрастает от 0.00797 мД в контрольном эксперименте до 0.11383 мД в образцах, полученных при шоковой (снятие давления за 2 секунды) декомпрессии, т.е. более чем на порядок (см. табл. 1): для гранитов рапакиви, соответственно, от 0.0233 мД и до 3.300 мД (табл. 2). Использованы средние значения по ряду экспериментов.

Средний радиус капилляров $\mathrm{R}_{\mathrm{k}}$ (см. табл. 1) стабильно растет от 0.040 до 0.169 и 0.204 мкм с уменьшением времени декомпрессии и одновременным повышением проницаемости, при этом расчетное число пор резко уменьшается, что связано с методикой расчета, поскольку вклад в проницаемость капилляров большого сечения на порядки выше «слепых» или пор минимального размера.

У гранодиоритов коэффициент открытой пористости практически одинаков в исходных образцах и составляет 4.4-4.7 \%. В контрольных экспериментах (см. табл. 1, образцы 1-6) коэффициент практически не меняется. С увеличением скорости декомпрессии до 500 атм/с резко увеличивается разброс значений коэффициента открытой пористости, уменьшаясь в образцах с максимальными значениями проницаемости. Вероятнее всего, это связано с тем обстоятельством, что при измерении проницаемости происходило значительное обжатие образца, что и обусловливало уменьшение измеряемого значения открытой пористости.
Отметим, что шоковая декомпрессия приводит к структурированию, выраженному не столько в количественном увеличении порового пространства, сколько в качественном изменении его конфигурации. Так, при малых скоростях декомпрессии проницаемость значительно увеличивается (см. табл. 1, образцы 1-6), но отсутствует система трещин по образцу. С увеличением скорости декомпрессии до $30 \mathrm{MПа/с} \mathrm{начинает} \mathrm{фор-}$ мироваться система пор или микро- и макротрещин, имеющая довольно отчетливую проводящую ориентировку (см. табл. 1, образцы 41-46). При дальнейшем уменьшении времени сброса давления и соответствующем увеличении скорости декомпрессии происходит закономерное увеличение проницаемости и величины раскрытия трещин $\mathrm{b}_{\mathrm{t}}$ до 0.3 мкм (см. табл. 1, образцы 31-36.)

Аналогичные явления наблюдаются для гранитоврапакиви (табл. 2), хотя влияние декомпрессии на свойства порового пространства отмечается при меньших ее скоростях. Вероятнее всего, это происходит ввиду значительного различия в размерах кристаллов, слагающих образцы гранита-рапакиви.

Следует также отметить, что при шоковой декомпрессии и изменении структуры пространства закономерно уменьшается прочность образцов. Для гранодиорита эта зависимость имеет нелинейный характер (рис. 4), что подчеркивает значимость скорости декомпрессии.

В последующем было проведено залечивание образцов, подвергнутых шоковой декомпрессии со скоростью $50 \mathrm{MПа/с} \mathrm{при} \mathrm{начальном} \mathrm{давлении} 100$ МПа и температуре $500{ }^{\circ} \mathrm{C}$ с целью определения возможности восстановления прочностных свойств породы в гидротермальных условиях.

В природе залечивание трещин может происходить в результате действия различных процессов. Основным фактором, определяющим закрытие микротрещин, является неоднородность поля напряжений, вызывающая растворение вещества в зонах концентрации напряжений, его перенос и отложение на бортах трещин. При подъеме гидротермального раствора в результате охлаждения растворимость кремнезема и других компонентов уменьшается, что приводит к выпадению осадка, осаждению его на стенках трещин и зарастанию или залечиванию трещин. Кроме того, упругие и другие физические свойства пород, возможности массопереноса связаны с геометрией порового пространства и общей пористостью и проницаемостью. Изученные процессы, вызывающие изменение морфологии трещин, могут сказываться и на величине этих характеристик. Экспериментально показано [Kotelnikova, Kotelnikov, 2008; Geguzin et al., 1988], что залечивание зависит от температуры, состава флюида и ориентации трещины. Этот процесс в силикатной среде может происходить путем диффузии через решетку и транспорта материала матрицы вдоль поверхности разграничения твердое - флюид или непосредственно через флюид и 


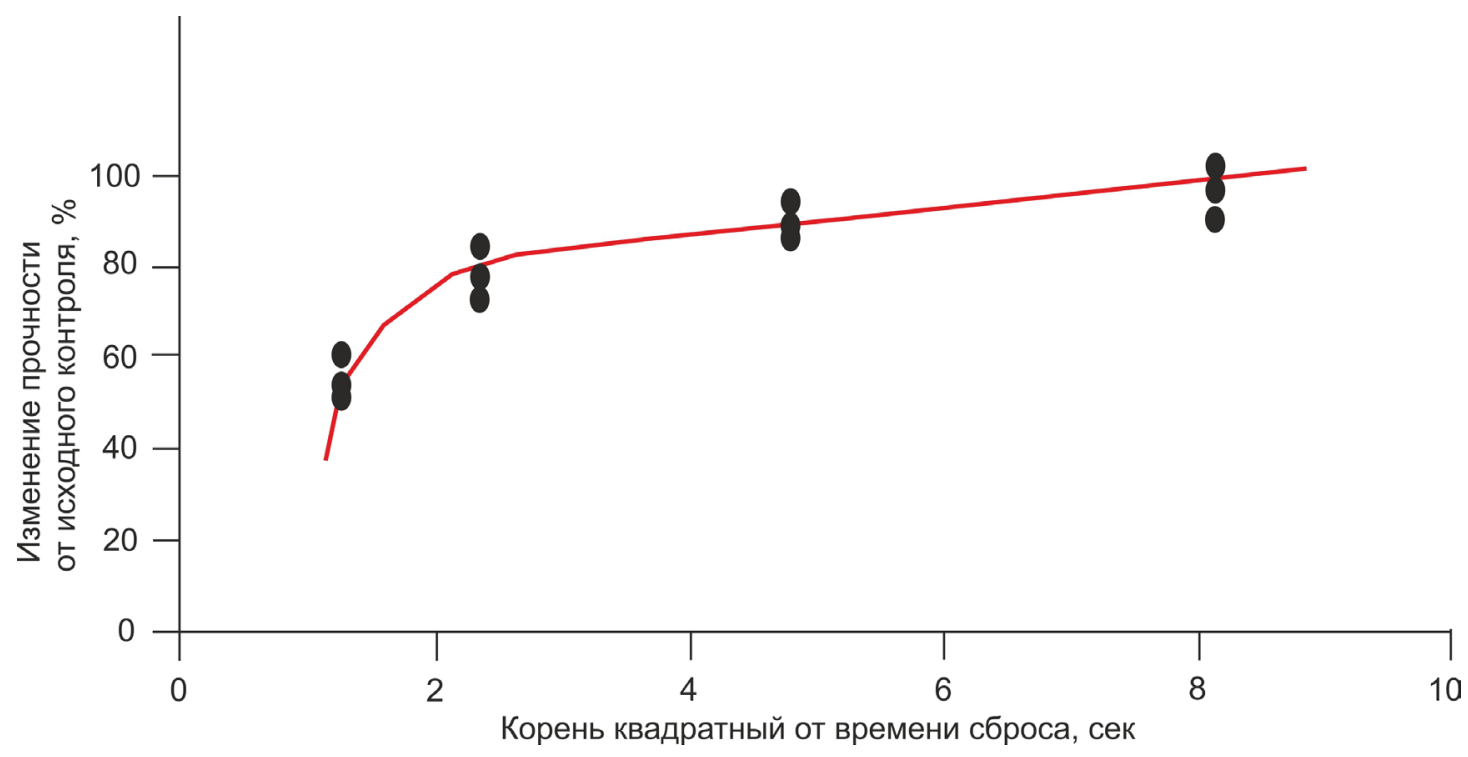

Рис. 4. Изменение прочности гранодиорита в зависимости от скорости сброса давления.

Fig. 4. Changes of granodiorite strength depending on pressure release rates.

не требует вовлечения нового матричного материала. При этом морфология трещины изменяется. Существует разность химического потенциала между передвигающимся концом трещины и ее стенками вследствие неровностей поверхности трещин:

$$
\Delta \mu=\gamma(\mathrm{Ce}-\mathrm{Cm}) \Omega,
$$

где $\gamma$ - поверхностная энергия, $\Omega$ - молекулярный объем, Ce, $\mathrm{Cm}$ - кривизна поверхности у перегибов и в средней части соответственно. Анализ уравнения показывает, что перенос вещества происходит от выпуклых или вогнутых участков с большой кривизной поверхности к выпуклым частям с низкой кривизной. Разная плотность дислокаций на стенках также является причиной разности химического потенциала [Geguzin et al., 1988]. В этой работе показано, что размер сужающейся поры в термоградиентном поле уменьшается до критического значения:

$$
\mathrm{Y} \cdot \mathrm{D} \sim(\nabla \mathrm{T})-1 / 2
$$

В случае залечивания эта зависимость является проявлением пороговости по отношению к растворению боковых стенок трещины. Практически из изложенного следует, что чем больше неровностей в трещине, тем мельче образованные включения. Если плотность дислокаций низка (105-106 см²), они практически не влияют на перемещение ступени растворения. В случае сильнодислоцированного кристалла можно считать, что дислокаций так много, что они равномерно распределены вдоль поверхности. Ступени растворения (роста) тогда образуются выходами дислокаций, и перемещаться эти ступени могут, если расстояние между дислокациями не меньше диаметра критического зародыша. Показано [Nichols, Mullins, 1965], что при залечивании трещин с образованием включений по отношению расстояния между включениями к радиусу $\lambda / \mathrm{R}$ можно судить о преобладании формы массопереноса: при $\lambda / \mathrm{R}=12.96$ имеет место диффузия через кристаллическую решетку, если отношение равно 9.02 диффузия идет через поровый раствор, при $\lambda / \mathrm{R}=8.89$ преобладает обмен поверхность-флюид. З.А. Котельникова [Kotelnikova, Kotelnikov, 2008], работая с призмами, выпиленными из монокристалла кварца и подвергнутыми термоудару для получения сети трещин, показала, что в случае залечивания флюидообразующей смесью разного состава средняя величина $\lambda / \mathrm{R}$ для 500-600 ${ }^{\circ} \mathrm{C}$ составила 9.0, что отвечает массообмену через флюид.

Поскольку в нашем случае предполагается перенос вещества через флюид, заполняющий поры, для описания его можно воспользоваться видоизмененной схемой, предложенной Я.Е. Гегузиным с соавторами [Geguzin et al., 1988] для оценки скорости движения включений в термоградиентном поле (тот же тип массопереноса), и дополненной уравнениями [Smith, Evans, 1984] для определения времени образования первых включений при залечивании. Длину залеченного участка L можно определить:

$$
\mathrm{L}=\Lambda[(\mathrm{t} \exp (-\mathrm{Q} / \mathrm{kT})) / \mathrm{T}]
$$

где $\Lambda$ и $\omega-$ константы, зависящие от начальной геометрии трещины; Q - энергия активации, для кварца по оценкам [Smith, Evans, 1984] равна 50 кДж/моль; T - абсолютная температура; $\mathrm{k}$ - константа Больцмана; $\mathrm{t}$ - время. 
V.Ya. Medvedev et al.: Experimental study of decompression, permeability and healing of silicate rocks... (v):

Тогда скорость перемещения замыкания трещины

$$
\mathrm{v}=\Lambda[(\mathrm{Q} / \mathrm{kT}) / \mathrm{T}]=\beta \omega\left(\mathrm{Y}-\mathrm{Y}^{*}\right)(\partial \mathrm{c} / \partial \mathrm{T}) \Delta \mathrm{T}
$$

где $\beta$ - коэффициент, определяемый экспериментально по углу наклона на графике v-R. Анализ этих зависимостей приводит к выводу, что скорость перемещения замыкания трещины (фактически скорость залечивания) линейно зависит от ширины трещины. В работе [Nichols, Mullins, 1965] показано, что коэффициент $\beta$ прямо зависит от плотности дислокаций в кристалле. Таким образом, залечивание в сильнодислоцированных кристаллах происходит быстрее. Скорость залечивания является функцией температуры, времени и концентрации раствора.

3.А. Котельниковой с А.Р. Котельниковым [Kotelnikova, Kotelnikov, 2008] была проведена серия экспериментов с целью разработки способов образования синтетических флюидных включений путем залечивания трещин в минерале. В качестве затравки использовались кристаллы кварца (пьезокварц, р. Алдан). Шихта приготовлялась из оксидов Si и Al, карбоната $\mathrm{Na}$ и гидрокарбоната К. В систему добавлялся фтор в виде $\mathrm{NaF}$ и $\mathrm{AlF}_{3}$. Эксперименты проводились в гидротермальных условиях при давлении 2 кбар (200 МПа). Изначально система была нагрета до $675^{\circ} \mathrm{C}$ и выдержана при одной температуре в течение 100 часов для уравновешивания расплава с материалом затравки. Затем проводилось ступенчатое (по 7-8 ${ }^{\circ} \mathrm{C}$ ) снижение температуры, и при каждой новой температуре система выдерживалась в течение 24-30 часов. По достижении $650{ }^{\circ} \mathrm{C}$ температура выдерживалась еще в течение 100 часов, и затем производилась закалка опытов. В результате в образце из пересыщенной водой системы все трещины и поры были полностью залечены.

Анализ приведенных выше данных позволил предположить, что в нашем случае следует ожидать интенсивного залечивания образцов за время порядка 1000 часов при создании оптимальных условий массопереноса.

Эксперимент осуществлялся по методике изобарноизотермической выдержки в контролируемой атмосфере в термоградиентных условиях.

Образцы, предварительно подвергнутые шоковой декомпрессии, в виде прямоугольников размещались вдоль автоклава (см. рис. 1). Залечивание гранодиоритов производилось в области гидротермального роста кварца и слюды при температуре $500{ }^{\circ} \mathrm{C}$, давлении 100 МПа в присутствии щелочного раствора. В качестве шихты как исходного материала для залечивания применялась смесь кварца, слюды и амфибола, которая помещалась на дно автоклава. Длительность эксперимента составляла 240 и 800 часов. После цикла залечивания на образцах отмечается рост новых фаз (преимущественно кварца) и замыкание в некоторых случаях устьев трещин. С увеличением времени гидро- термальной обработки прочность образцов увеличивается до 60 \% от исходной прочности гранодиорита. Ввиду того, что с увеличением длительности эксперимента происходит выполаживание кривой, дальнейшего увеличения прочности образцов не следовало ожидать и эксперименты длительностью более 800 часов не проводились.

\section{4. ОБСУЖДЕНИЕ РЕЗУЛЬТАТОВ}

Проведенные петрофизические эксперименты по декомпрессии показали, что в образцах, подвергнутых шоковой декомпрессии со скоростью до $50 \mathrm{MПа} / \mathrm{c}$, наблюдается обилие мелких внутризерновых трещин, распространенных по всем слагающим породу минералам; развитие более крупных (до 0.12-0.15 мм) межзерновых трещин, переходящих в поры, и сквозных субпараллельных трещин, секущих все минералы образца. Иными словами, такая декомпрессия приводит к структурированию, выраженному не столько в количественном увеличении порового пространства, сколько в качественном изменении его конфигурации. Формируется система пор или микро- и макротрещин, имеющая довольно отчетливую проводящую ориентировку, что закономерно отражается на их физических свойствах. Резко меняются проницаемость, открытая пористость и другие параметры. Соответственно меняется и прочность образцов. Можно отметить, что эти эффекты нелинейно зависят от скорости сброса давления и, вероятно, при больших скоростях декомпрессии, существующих в природе, должны проявляться более значительно.

Как показывает опыт изучения условий формирования разнообразных рудных месторождений гидротермального типа, приуроченных к зонам разломов в интервале глубин 1-5 км, их становление происходило многостадийно и на протяжении длительного времени. [Kushnarev, 1982]. В природных условиях процесс залечивания сегментов разломов во многом сходен с условиями формирования рудных месторождений. Таким образом, небольшие трещины и поры при благоприятных условиях могут залечиваться в течение недель-месяцев в прерывистом режиме, тогда как крупные сегменты разломов, вскрывшиеся, например, при сильных землетрясениях, могут находиться в стадии залечивания в условиях зеленосланцевой фации метаморфизма в течение многих десятков, сотен или тысяч лет. Влияние скорости тектонического крипа на длительность залечивания разрывных нарушений в зонах разломов отмечалось в работе [Kocharyan, 2010]. Ее автором было показано, что высокие скорости крипа, порядка $\mathrm{V} \geq 25$ мм/год, способны значительно снизить эффективность залечивания.

Таким образом, ответы на вопросы о длительности залечивания разломов всегда требуют уточнения различных параметров с учетом термо- и барометрических градиентов, из-за разнообразных сочетаний кото- 
рых может быть дан только приблизительный ответ [Ruzhich et al., 1990, 2014; Kocharyan, 2009]. Важно учитывать, что при гидротермально-метасоматическом залечивании на глубинах порядка 5-10 км прочность пород на сжатие может восстанавливаться примерно до уровня 0.6-0.7 от исходной, что указывает на возможность соответствующего уменьшения сдвиговой прочности в тех сегментах разломов, где проявлялась декомпрессия.

Следует заметить, что в контактных пятнах скольжения на неровностях плоскостей разломов при высоких давлениях и темпах деформаций, а также при быстрых смещениях маловероятно проявление декомпрессионного залечивания трещинно-поровых образований. В подобных условиях реализуется иной трибохимический процесс. Имеются в виду процессы ускоренного преобразования вещества в условиях сильного сжатия и трения в плоскостях зеркал скольжения при высокоскоростных динамических подвижках. В таких случаях в глубинных сегментах сейсмоактивных разломов на поверхности зеркал скольжения при сверхтонком измельчении минералов до размеров, измеряемых первыми нанометрами, фиксируется наличие тончайших обводненных слоев из преобразованных минеральных фаз, обладающих пониженным сопротивлением сдвигу [Sobolev et al., 2011, 2014].

\section{5. ЗАКЛЮЧЕНИЕ}

На основе полученных результатов о шоковой декомпрессии, запускающей возникновение активных транспортных путей в земной коре и проявленной в зонах внутрикоровых разломов и разломных пересечений, необходимо подчеркнуть,что подобные процессы могут быть кратковременными, но за период своего существования они способны за короткое время, например при сейсмической активизации, переместить значительные количества как инертного, так и химически активного вещества в разрывных нарушениях разного масштаба.

В рассмотренных выше экспериментах были созданы достаточно идеальные условия для быстрого, в течение нескольких недель, залечивания небольших по объемам образцов. Этот параметр может использоваться в качестве отправной точки при расчетах времени восстановления сплошности земной коры с учетом сложной комбинации различных факторов. Значимость каждого из перечисленных факторов еще предстоит изучить при проведении дальнейших экспериментов.

Интерпретируя полученные результаты, следует заметить, что в зонах разломов явления декомпрессионного залечивания возникают за пределами пятен контактного скольжения на неровностях. Однако именно в них в условиях сильнейшего деформирования и разогрева происходят сложные трибохимические процесссы, которые определяют уровень сдвигового сопротивления и режим концентрации сдвиговых напряжений. Процессы декомпрессионного залечивания в разломах земной коры, по-видимому, не являются определяющими при подготовке масштабного динамического разрушения высоконапряженных массивов горных пород.

\section{6. ЛИTEPATУРA / REFERENCES}

Balyshev S.O., Medvedev V.Ya, Savel'eva V.B., 1996. On the problem of shock decompression of silicate rocks. Doklady AN 347 (1), 66-68 (in Russian) [Балышев С.О., Медведев В.Я., Савельева В.Б. К проблеме декомпрессии силикатных пород // Доклады АН. 1996. Т. 347. № 1. С. 66-68].

Geguzin Ya.E., Kaganovsky Yu.S., Kruzhanov V.S., 1988. About the temperature relationship for NaCl crystals of the equilibrium shape. Kristallografiya 33 (6), 1495-1498 (in Russian) [Гегузин Я.Е., Кагановский Ю.С., Кружанов В.С. О температурной зависимости равновесной формы кристаллов $\mathrm{NaCl} / /$ Кристаллография. 1988. Т. 33. Вып. 6. С. 14951498].

Kocharyan G.G., 2009. Mechanisms of strength recovery of seismogenic faults. In: Problems of interacting geospheres. GEOS, Moscow, p. 77-86 (in Russian) [Кочарян Г.Г. Механизмы восстановления прочности сейсмогенных разломов // Проблемы взамодействующих геосфер. М.: ГЕОС, 2009. С. 77-86].

Kocharyan G.G., 2010. Fault zone as a nonlinear mechanical system. Fizicheskaya Mezomekhanika 13 (Special Issue), 5-17 (in Russian) [Кочарян Г.Г. Разломная зона как нелинейная механическая система // Физическая мезомеханика. 2010. Т. 13. Специальный выпуск. С. 5-17].

Kotelnikova Z.A., Kotelnikov A.R., 2008. NaF-bearing fluids: Experimental investigation at $500-800{ }^{\circ} \mathrm{C}$ and $P=2000$ bar using synthetic fluid inclusions in quartz. Geochemistry International 46 (1), 48-61. http://dx.doi.org/10.1134/S00167 02908010047.

Kushnarev I.P., 1982. Depths of Formation of Endogenous Ore Deposits. Nedra, Moscow, 166 p. (in Russian) [Кушнарев И.П. Глубины образования эндогенных рудных месторождений. М.: Недра, 1982. 166 с.].

Letnikov F.A., Kuznetsov K.E., Medvedev V.Ya., 1990. On the problem of shock decompression of fluidized silicate melts. Doklady AN SSSR 313 (3), 682-684 (in Russian) [Летников Ф.А., Кузнецов К.Е., Медведев В.Я. К проблеме шоковой декомпрессии флюидизированных силикатных расплавов // Доклады АН СССР. 1990. Т. 313. № 3. С. 682-684]. 
Medvedev V.Ya., Balyshev S.O., Savelieva V.B., 1995. Change of physical properties of rocks under shock decompression. In: The 13th Russian Meeting on Experimental Mineralogy. IEM RAS, Chernogolovka, p. 68 (in Russian) [Медведев В.Я., Балышев С.О., Савельева В.Б. Изменение физических свойств горных пород при шоковой декомпрессии // XIII Российское совещание по экспериментальной минералогии. Черноголовка: ИЭМ РАН, 1995. С. 68].

Nichols F.A., Mullins W.M., 1965. Morphological changes of a surface of revolution due to capillarity-induced surface diffusion. Journal of Applied Physics 36 (6), 1826-1835. http://dx.doi.org/10.1063/1.1714360.

Ruzhich V.V., Ivanova L.A., Medvedev V.Ya., 2014. On the study of tribological processes in slickensides from fault zones. In: Faulting in the lithosphere and related processes. Tectonophysical analysis. Abstracts of the All-Russia meeting with visiting researchers from other countries (11-16 August 2014, Irkutsk). IEC SB RAS, Irkutsk, p. 65 (in Russian) [Ружич B.В., Иванова Л.А., Медведев В.Я. Об изучении трибологических процессов в зеркалах скольжения из зон разломов // Разломообразование в литосфере и сопутствующие процессы: тектонофизический анализ: Тезисы докладов Всероссийского совещания с участием приглашенных исследователей из других стран (11-16 августа 2014 г., г. Иркутск). Иркутск: ИЗК СО РАН, 2014. С. 65].

Ruzhich V.V., Medvedev V.Ya., Ivanova L.A., 1990. Healing of seismogenic fractures and repeatability of earthquakes. In: Seismicity of the Baikal rift: prognostic aspects. Nauka, Novosibirsk, p. 44-50 (in Russian) [Ружси В.В., Медведев В.Я., Иванова Л.А. Залечивание сейсмогенных разрывов и повторяемость землетрясений // Сейсмичность Байкальского рифта: прогностические аспекты. Новосибирск: Наука, 1990. С. 44-50].

Ruzhich V.V., Truskov V.A., Chernykh E.N., Smekalin O.P., 1999. Recent movements in the fault zones of Pribaikalie and mechanisms of their initiation. Geologiya i Geofizika (Russian Geology and Geophysics) 40 (3), 360-372.

Smith D., Evans B. 1984. Diffusional crack healing in quartz. Journal of Geophysical Research 89 (B6), $4125-4135$. http://dx.doi.org/10.1029/JB089iB06p04125.

Sobolev G.A., Genshaft Yu.S., Kireenkova S.M., Morozov Yu.A., Smul'skaya A.I., Vittegren’ V.I., Kulik V.B., 2011. Effects of high pressure and temperature on properties of nanocrystals in rocks: Evidences from Raman spectroscopy. Izvestiya, Physics of the Solid Earth 47 (6), 465-474. http://dx.doi.org/10.1134/S1069351311050053.

Sobolev G.A., Vettegren V.I., Ruzhich V.V., Ivanova L.A., Mamalimov R.I., Shcherbakov I.P., 2014. The study of nanocrystals in slickensides. In: The 15th International Conference "Physical, chemical and petrophysical studies in Earth Sciences". Moscow, September 29 - October 01, 2014. Conference Proceedings. IGEM RAS, Moscow, p. 211-213 (in Russian) [Соболев Г.А., Веттегрень В.И., Ружич В.В., Иванова Л.А., Мамалимов Р.И., Щербаков И.П. Исследование нанокристаллов в зеркале скольжения // Пятнадцатая международная конференция «Физико-химические и петрофизические исследования в науках о Земле». Москва, 29 сентября - 1 октября 2014 г. Материалы конференции. М.: ИГЕМ РАН, 2014. С. 211-213].

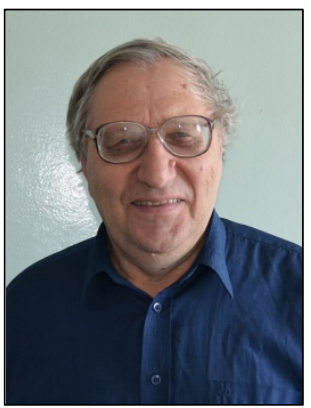

Медведев Владимир Яковлевич, канд. геол.-мин. наук, с.н.с.

Институт земной коры СО РАН

664033, Иркутск, ул. Лермонтова, 128, Россия

\e-mail:med@crust.irk.ru

Medvedev, Vladimir Ya., PhD in Geology and Mineralogy, Senior Researcher

Institute of the Earth's Crust SB RAS

128 Lermontov street, Irkutsk 664033, Russia

\e-mail:med@crust.irk.ru

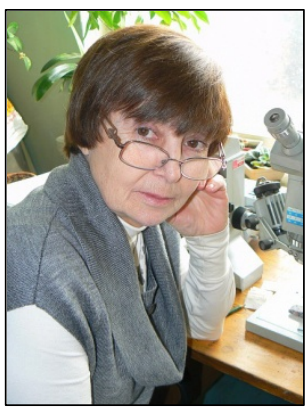

Иванова Лариса Александровна, канд. геол.-мин. наук, с.н.с.,

Институт земной коры СО РАН

664033, Иркутск, ул. Лермонтова, 128, Россия

e-mail: liva@crust.irk.ru

Ivanova Larisa A., PhD in Geology and Mineralogy, Senior Researcher

Institute of the Earth's Crust SB RAS

128 Lermontov street, Irkutsk 664033, Russia

e-mail: liva@crust.irk.ru 


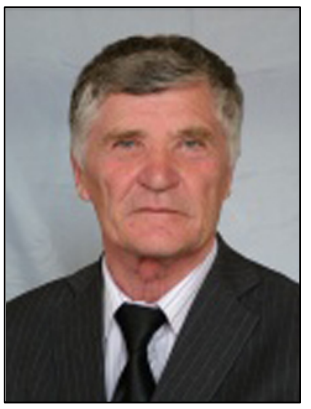

Лысов Борис Антонович, канд. геол.-мин. наук, доцент кафедры геологии нефти и газа ИГУ Иркутский государственный университет, геологический факультет 664003, Иркутск, ул. Ленина, 3, Россия

Тел.: 8(3952)243280

Lysov, Boris A., PhD in Geology and Mineralogy, associate professor

Irkutsk State University, Geological Faculty

3 Lenin street, Irkutsk 664003, Russia

Tel.: 8(3952)243280

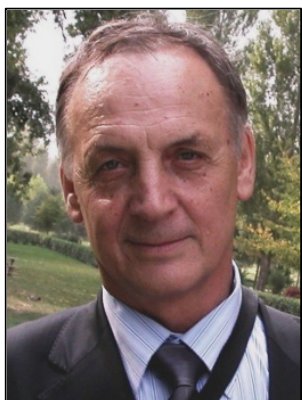

Ружич Валерий Васильевич, докт. геол.-мин. наук, г.н.с.

Институт земной коры СО РАН

664033, Иркутск, ул. Лермонтова, 128, Россия

Тел. (3952)422776; e-mail: ruzhich@crust.irk.ru

Ruzhich, Valery V., Doctor of Geology and Mineralogy, Chief Researcher Institute of the Earth's Crust SB RAS

128 Lermontov street, Irkutsk 664033, Russia

Tel.+7(3952)422776; e-mail: ruzhich@crust.irk.ru

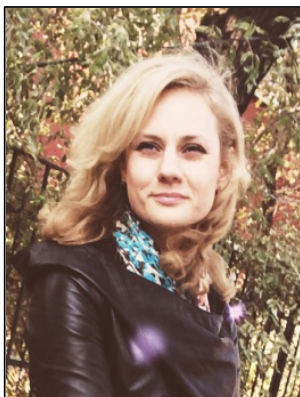

Марчук Марина Валерьевна, канд. геол.-мин. наук, м.н.с.

Институт земной коры СО РАН

664033, Иркутск, ул. Лермонтова, 128, Россия

Marchuk, Marina V., PhD in Geology and Mineralogy, Junior Researcher Institute of the Earth's Crust SB RAS

128 Lermontov street, Irkutsk 664033, Russia 